\title{
Indirect Procurement: A Literature Review and Study of Trends
}

\author{
Dan Israel1, Sime Curkovic ${ }^{2}$ \\ ${ }^{1}$ Management Department, Center for Integrated Supply Management, Haworth College of Business, Western Michigan \\ University, Kalamazoo, USA \\ ${ }^{2}$ Haworth College of Business, Western Michigan University, Kalamazoo, USA \\ Email: daniel.a.israel@wmich.edu,sime.curkovic@wmich.edu
}

How to cite this paper: Israel, D., \& Curkovic, S. (2020). Indirect Procurement: A Literature Review and Study of Trends. American Journal of Industrial and Business Management, 10, 775-792.

https://doi.org/10.4236/ajibm.2020.104052

Received: March 23, 2020

Accepted: April 18, 2020

Published: April 21, 2020

Copyright (C) 2020 by author(s) and Scientific Research Publishing Inc. This work is licensed under the Creative Commons Attribution International License (CC BY 4.0).

http://creativecommons.org/licenses/by/4.0/

Open Access

\begin{abstract}
Indirect procurement is a diverse and crucial component of purchasing that has been largely ignored by scholarly research, due to representing only a small portion of manufacturing firms' expenditures. Indirect purchasing also suffers from confusing nomenclature that makes drawing conclusions from multiple sources difficult. Proper management of indirect spending allows for sustainable competitive advantages and reduced costs. By performing a keyword search in multiple comprehensive databases, we analyzed, consolidated, and summarized the current areas of research as it pertains to indirect procurement. We also identified areas for future research by identifying gaps from our analysis. We find that much of the current research has focused on the procurement of Maintenance, Repair, and Operating (MRO) items and Information Technology (IT). MRO purchasing was also found to have confusing nomenclature, as the term can be used to refer to very different types of purchases. We make distinctions between these types and draw conclusions accordingly. For both MRO and IT research, we found that most research focuses on supplier relationship management, as well as the optimal degree of employee involvement in these purchases. While many studies stress the importance of properly managing indirect suppliers and engaging all stakeholders in indirect purchasing decisions, very few provide a successful framework for doing so. This paper serves multiple purposes. First, it seeks to consolidate and provide new definitions for indirect procurement terms in order to make future scholarly research easier. Second, it seeks to understand what research has been completed already in this field, and synthesizes the research into meaningful groups. Finally, it identifies areas for future research. This is an important endeavor because we seek to summarize and refocus a burgeoning field of study, allowing future researchers to easily understand what has already been studied.
\end{abstract}




\section{Keywords}

Indirect Procurement, Indirect Spend, MRO, Information Technology, E-Procurement, COPC Inc.

\section{Introduction}

In recent years, the strategic importance of purchasing has increased, and has often been the source of competitive advantage (Sitar, 2012). A firm's purchases can be classified as either direct or indirect procurement. Direct procurement can be defined as revenue-generating expenditures, or expenditures that relate directly to the product or service being sold (Cox, Chicksand, Ireland, \& Davies, 2005; Xideas \& Moschuris, 1998). Direct procurement has been more thoroughly studied in the literature and is far better understood in industry, for a multitude of reasons (de Boer, Holmen, \& Sitar, 2003; Gunasekaran \& Ngai, 2008). First, most procurement research has been done in the manufacturing industry, which typically consists of a large proportion of direct spend to total spend (Cox et al., 2005). Second, established cost-based accounting procedures and current IT technologies allow for easier tracking and analysis of costs that directly impact end products (Agndal \& Nilsson, 2007; Kim \& Shunk, 2003; Segev \& Gebauer, 2000). Third, the purchasing of direct items is usually centralized and supported by the organizational structure of the organization, as direct procurement has more often been perceived as strategic to financial performance (de Boer et al., 2003; Kim \& Shunk, 2003). For these and other reasons, direct procurement is more properly defined and better understood by both academia and industry.

Alternatively, indirect procurement can be defined as non-revenue-generating expenses, or expenditures that do not relate directly to the product or service being sold (Cox et al., 2005; Xideas \& Moschuris, 1998). There have been fewer studies done on indirect procurement, and the topic is far less understood by academia and industry (de Boer et al., 2003; Gunasekaran \& Ngai, 2008). This lack of understanding is due in part to confusing terminology; "indirect procurement" or "indirect spend" is a blanket term that can refer to any number of goods or services. Segev and Gebauer (2000) defined indirect spend most succinctly by including the following:

1) Maintenance, repair, and operating (MRO) supplies;

2) Capital equipment;

3) Services.

However, many articles refer to indirect spending (or subcategories thereof) by different names, making keyword searches and drawing conclusions difficult. "MRO" can be used to refer to a subcategory of indirect spend (e.g. Gunasekaran, McGaughey, Ngai, \& Rai, 2009; Yu, Mishra, Gopal, Slaughter, \& Mukhopadhyay, 2015), or used synonymously with the entirety of indirect spend (e.g. Cox et al., 2005; Yates, 1998). The latter is more common in older articles but 
remains prominent today. Other terms for indirect spending include "non-product related” spending (Xideas \& Moschuris, 1998), "service purchasing” (Thomas, Mason-Jones, Davies, \& John, 2015), “operating resources” (Segev \& Gebauer, 2000), as well as being referred to implicitly when referring to the outsourcing of certain industries (e.g. Cheng, Barton, \& Prabhu, 2010; Qu, Pinsonneault, \& Oh, 2011).

Despite its smaller proportion to total spending, many firms and scholars are beginning to realize the cost-savings potential of indirect spending. While direct spending accounts for a majority value of a firm's purchases, indirect spend accounts for the majority number of purchases an organization makes (Barry, Cavinato, Green, \& Young, 1996; Cox et al., 2005). Van Weele (2005) found that indirect purchases account for 80 percent of all purchases, while representing only $20 \%$ of dollar value. Indirect spend, therefore, consists of a high frequency of low-value purchases, which requires significant time commitments from a large part of the organization (Bechtel \& Patterson, 1997). An optimized indirect purchasing strategy would therefore result in significant time and organizational resources being saved. This is considered more of a "soft" savings; a reduction of internal processing times rather than monetary savings through a reduction in purchase price (Porter, 1999). In addition to the high frequency of purchases, indirect spending also consists of low frequency purchases of high importance, such as the procurement of information technology (IT). Nakata, Zhou, and Kraimer (2008) found that higher IT capability corresponds significantly with greater market and financial performance. IT procurement, therefore, is a crucial component of a firm's success. Thus, indirect spend consists of both high and low-volume purchases with varying levels of importance.

Problems with defining indirect spend make it difficult to develop strategies to control indirect spending. Cox et al. (2005) found that around 10 percent of companies lacked any strategy at all for managing indirect spend, and that many selected their strategies simply on hunches rather than empirical evidence. Hingorani (2010) highlights the difficulty and importance of analyzing indirect costs. A lack of procurement strategies for indirect spending leads to issues such as maverick purchasing, or the purchasing of goods and services outside of established contracts or procedures (Karjalainen, Kemppainen, \& van Raaij, 2009). These purchases are harmful to the organization because they circumvent established best practices, and make analyzing indirect spend more difficult (Sodhi, Sodhi, \& Tang, 2014). Additionally, many strategies for indirect procurement tend to focus solely on minimizing purchase price, rather than looking at the costs to the whole system (Bailey \& Helms, 2007; Bechtel \& Patterson, 1997). Strategies must be tailored to each individual subcomponent of indirect spend, and will vary based on a firm's industry and value of the purchased item (Al-Kaabi, Potter, \& Naim, 2007a; Hawkins, Nissen, \& Rendon, 2014; Moon, Swar, Chloe, Chung, \& Jung, 2010; Sitar, 2012; Thomas et al., 2015; van der Valk \& Rozemeijer, 2009).

This paper serves multiple purposes. First, it seeks to consolidate and provide 
new definitions for indirect procurement terms in order to make future scholarly research easier. Second, it seeks to understand what research has been completed already in this field, and synthesize the research into meaningful groups. Finally, it identifies areas for future research. This is an important endeavor because we seek to summarize and refocus a burgeoning field of study, allowing future researchers to easily understand what has been studied up to this point in time.

\section{Current Areas of Study}

We performed comprehensive keyword searches in literature databases. This involves searching for keywords associated with indirect procurement, identifying applicable articles, and using the keywords associated with those articles to expand the search. This paper finds that the primary topics of study within indirect procurement have been in the fields of MRO and IT procurement, with many studies focusing on a firm's relationships with its suppliers and the level of employee involvement with purchasing.

\subsection{Maintenance, Repair, and Operations (MRO)}

Like indirect procurement, MRO has been an understudied topic in the literature (Yu et al., 2015). And like indirect procurement, MRO has issues with its definition that make synthesizing scholarly articles difficult. When not being used as a blanket term for all of indirect spending (Cox et al., 2005; Yates, 1998), it primarily refers to two very different components of indirect spending. In this paper, we refer to the first component as "Non-Critical MRO" and the second component as "Tooling MRO". When analyzing scholarly research on MRO, it is important to note which type of MRO is being referred to (Segev \& Gebauer, 2000). Both have very different characteristics and levels of importance, and require different strategies in order to manage properly. These strategies will differ based on their perceived importance to the firm (Al-Kaabi et al., 2007b; Bechtel \& Patterson, 1997).

\subsubsection{Non-Critical MRO}

$\mathrm{Yu}$ et al. (2015) describe this component of MRO purchasing to include "low value, non-critical, high volume goods (e.g., office supplies), costly and specialized goods (e.g., electronic items, including printers and photocopiers), and services (e.g., security and cleaning)." While this is remarkably similar to the Segev and Gebauer (2000) definition of indirect spending as a whole, this definition of MRO focuses more on back-office purchases than those that affect manufacturing. If the company would abstain from making these purchases, problems may not arise immediately. Croom (2001) highlights the high variety of goods that are purchased for these purposes, and multiple researchers highlight the high transaction costs relative to purchase price (Essig, Glas, \& Gutsmiedl, 2015; Sodhi et al., 2014). Non-critical MRO, especially low value purchases such as office goods, make up a majority of the purchases an organization makes, while only 
accounting for a small minority of costs (Barry et al., 1996). Palmer and Ward (1997) cite a case where $81 \%$ of MRO invoices were below $\$ 1000$. Non-critical MRO purchases are the reason that indirect spending as a whole is commonly thought of as high-volume and low-value. As discussed, this is not always the case.

The purchasing of non-critical MRO items may not be completed by the purchasing department (Bechtel \& Patterson, 1997; Segev \& Gebauer, 2000). Since these purchases are typical of low-value, some companies seek to empower the end users of such products to make the purchases for themselves. The research on how best to control non-critical MRO spending is inconclusive (Anonymous, 2015); should companies decentralize purchasing and allow employees to purchase items for themselves, or should they centralize purchasing and strictly control the spend from the purchasing department? The primary issue associated with decentralized purchasing is the occurrence of non-compliant purchasing, commonly referred to as maverick buying. The most comprehensive paper on maverick buying was by Karjalainen et al. (2009), which defines maverick buying as "the off-contract buying of goods and services for which an established procurement process is in place based on pre-negotiated contracts with selected suppliers." Maverick buying has been found to increase a firm's purchasing costs and decrease purchasing leverage. The authors cite Angeles and Nath (2007) who found that when compared to compliant purchasing, noncompliant purchasing can raise costs as much as $20 \%$. Maverick buying has been found to be more prevalent in indirect purchases in general, and non-critical MRO purchases specifically (e.g. Cox et al., 2005; de Boer et al., 2002). There are many potential reasons for the occurrence of maverick buying, and each reason has different solutions. The primary reasons identified by Karjalainen et al. (2009) from most common to least common can be found in Figure 1 below.

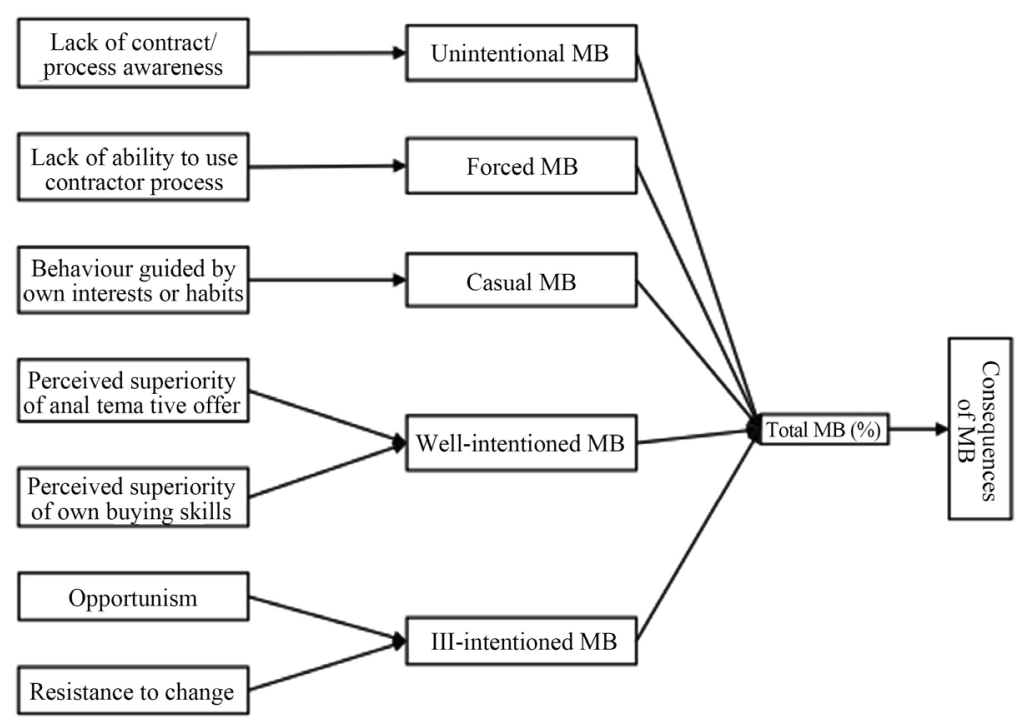

Figure 1. Different forms of maverick buying and their underlying reasons, Karjalainen et al. (2009). 
Arguments to centralize non-critical MRO purchasing often seek to directly reduce costs and increase supplier leverage at the expense of expediency. In a centralized model, the purchasing department can monitor and control how these purchases are handled over the whole system, managing things such as order quantity, inventory levels, and logistics (Bechtel \& Patterson, 1997; Essig et al., 2015). Using this strategy, companies seek to reduce the effects of maverick buying. Formulas such as Economic Order Quantity (EOQ), a technique used prevalently for direct spend items to control inventory levels and order frequency, is impossible to calculate when separate entities are buying for themselves (Sodhi et al., 2014). Centralized purchasing also allows for a systems-based approach to inventory management. Many companies simply seek to reduce purchase price, and few take a Total Cost of Ownership (TCO) approach to indirect purchasing. Bechtel and Patterson (1997) found that searching for, receiving, stocking, and distribution of non-critical MRO items account for $96.6 \%$ of the total cost of ownership. These are concerns not addressed through most decentralized purchasing models. Additionally, logistics must also be considered when purchasing these items, given the high frequency of orders. Managing less-than-full truck load capacities is a frequent concern that can be more effectively addressed through a centralized purchasing model (Sarkar \& Mohapatra, 2008).

Arguments to decentralize non-critical MRO purchasing often seek to increase expediency of ordering while attempting to adhere to pre-negotiated contracts in order to keep costs low. As mentioned previously, the effectiveness of adhering to these contracts is questionable. The most commonly suggested remedy to maverick purchasing has been the implementation of e-procurement tools (Angeles \& Nath, 2007). If a business was able to prevent maverick purchasing while maintaining decentralized purchasing of non-critical MRO items, the business would be able to achieve low costs and high transactional speeds. One method to achieve this is the use of charge cards, or corporate credit cards. Employees are empowered to purchase items that they need, but spending is controlled through credit limits; allotted budgets for each month or quarter that when reached, do not allow for any additional purchases. Palmer and Ward (1997) and Yates (1998) argue for this approach, arguing that although supplier leverage is reduced as compared to centralized purchasing, there will be a large reduction time in the time spent on these purchases. This is supported by Bechtel and Patterson (1997)'s research, where initial purchase price is not the primary component of a firm's total cost of ownership. Considering the reduction in time spent on these purchases given the high frequency of orders, this argument seems compelling (Barry et al., 1996; Cox et al., 2005).

\subsubsection{Tooling MRO}

More referring to the "Maintenance" and "Repair" of "Maintenance, Repair, and Operations", tooling MRO is typically classified as strategically important, low- 
volume goods of any value that are used to maintain and upkeep the tools used to manufacture products (Ayeni, Ball, \& Baines, 2016). If the company would abstain from making these purchases, significant problems may arise rapidly. Losing out on sales due to downtime is the primary concern when purchasing tooling MRO (Sople, 2016). The primary question with tooling MRO is how to minimize downtime while keeping inventory levels reasonable (Al-Kaabi et al., 2007b). Having multiples of every spare part a company could need readily accessible would ensure uptime, but would also ensure an inflated inventory level. Combined with unpredictable demand patterns, the inventory problem becomes a difficult one (Sople, 2016).

How businesses approach tooling MRO largely depends on their industry and the level of importance these types of purchases represent. For example, nonmanufacturing businesses are not involved with tooling MRO at all. The most robust tooling MRO research is in the industries where downtime has a significantly negative impact on business performance, such as the aeronautical, defense, automotive, electronics, and petroleum industries (Rezaei Somarin, Asian, Jolai, \& Chen, 2018). A strong majority of the current scholarly research focuses on the aerospace industry (e.g. Ayeni et al., 2016; Palma-Mendoza \& Neailey, 2015). This makes sense, as tooling MRO in the airline industry has the additional responsibility of ensuring the safety of passengers. Because of this growing amount of research, the aerospace industry can serve as a framework for lessdeveloped industries (Thomas et al., 2015). Current tooling MRO research focuses on topics such as the proper level of outsourcing, contract strategy, and applying management tools such as Lean and Six Sigma.

Outsourcing is a growing trend in the world of tooling MRO (Al-Kaabi et al., 2007a; Al-Kaabi et al., 2007b; Rezaei Somarin et al., 2018), with more companies prioritizing ongoing service relationships with the outsourced suppliers and moving away from simple transactional ones. Instead of paying for the price of spare parts, tooling MRO suppliers are charged a service fee; suppliers are paid a certain amount to ensure that their machines meet a certain service level. Many companies see this as a way to reduce both downtime and inventory costs, as spare parts are now the supplier's responsibility (MacDonnell \& Clegg, 2007). Thus, tooling MRO suppliers' responsibilities have shifted from the manufacturing to the service industry (Cheng et al., 2010; Thomas et al., 2015). This has required an increased focus on customer satisfaction throughout the suppliers' organizations, as there are more points of contact between supplier and customer than ever before (Guo \& Ng, 2011). Additionally, tooling MRO contracts are more complex and go beyond fixed-price purchasing (Sharifi, Kwon, \& Jardine, 2016). Flexibility is a crucial component of these contracts since failures and outages are difficult to predict with accuracy (Rezaei Somarin et al., 2018).

The shift towards a longer-term relationship with tooling MRO suppliers has introduced new models for managing these purchases. MacDonnell and Clegg (2007) present an interesting framework for rotable parts in aerospace mainten- 
ance; parts and tools that are not wholly consumed and can be repaired and reused. These parts are swapped out for working ones by the tooling MRO supplier, fixed, and swapped back when the new part shows signs of wear. This model reduces inventory and ordering costs by reducing the number of tools needed to maintain a machine, and allows for an easier management of a firm's tools. However, these kinds of supply chains have their challenges to implement. Most Enterprise Resource Planning (ERP) systems are not equipped for rotable parts as they are designed for one-directional material flow. In addition, the erratic demand patterns of non-critical parts prove another problem for ERP systems (Razi \& Tarn, 2003). The rotational kind of supply chain is only made possible through complex contracting and close relationships between supplier and customer (Guo \& Ng, 2011; Palma-Mendoza \& Neailey, 2015).

\subsubsection{Summary of Non-Critical and Tooling MRO}

When reading scholarly articles on MRO, it is important to understand which type of MRO is being referred to. Some articles are referring to the low-value, low-importance, high-volume parts of non-critical MRO, while others are referring to the high-importance, low-volume parts of tooling MRO. The distinction is important, because each category of MRO is managed differently. Although both areas are gaining momentum in scholarly research, the current research finds that the primary method of reducing costs of non-critical MRO is through the use of e-procurement technologies and restructuring the purchasing of these goods. The primary method of reducing costs of tooling MRO is through restructuring contracts and developing closer relationships with tooling suppliers.

\subsection{Information Technology (IT)}

The other rapidly growing area of research in indirect purchasing is the study of IT procurement (Wu, Yeniyurt, Kim, \& Cavusgil, 2006). The advent of the internet changed much of how businesses operate, and the benefits have been well documented in scholarly research and recognized by industry (Oh, Yang, \& Kim, 2014). IT capability has been found to be significantly correlated with greater market and financial performance, and represents the single largest capital investment by businesses today (Han, Kauffman, \& Nault, 2011; Nakata, Zhu, \& Kraimer, 2008). IT has allowed suppliers and customers to connect and compete in entirely new ways. Carayannis and Popescu (2005) state the following about how IT has changed the landscape of supplier/customer interaction:

When used for public procurement, information technology can be utilized as a means to achieve the main principles of perfect competition, namely, access to information, no barriers to entry (transparency), and a large number of participants in a market exchange.

The scholarly research that has been completed has focused on the IT procurement technologies that are available in the marketplace, these systems' advantages and disadvantages, the value of IT procurement to a business, and how best to utilize the selected IT technologies within an organization and beyond. 


\subsubsection{Available IT Procurement Technologies}

Currently, the most commonly studied IT application within procurement is ERP systems, which support the capabilities and processes utilized by a firm to function (Bendoly \& Schoenherr, 2005). ERP systems have had the most significant impact on the procurement of low-value, high-volume goods such as noncritical MRO items (Rajkumar, 2001; Segev \& Gebauer, 2000). The use of such systems has reduced the ordering costs of these items (Croom, 2000). In one case, the application of ERP systems was found to reduce transactional costs of non-critical MRO purchases by 66\% (Bendoly \& Schoenherr, 2005; Croom, 2001). This is particularly impactful for decentralized purchasing models that rely on higher purchasing frequencies of lower volumes.

Beyond ERP systems, many e-procurement technologies have been developed, and are constantly changing. Common applications include e-catalogs, e-auctions, e-marketplaces, e-MRO, e-sourcing, e-tendering, e-informing, etc. (de Boer, Harink, \& Heijboer, 2002; Rajkumar, 2001). These definitions change from author to author, and as the technology develops, new applications are added (Lancioni, Smith, \& Schau, 2003). E-auctions, commonly referred to as e-reverse auctions, are events where multiple suppliers offer competitive bids for a buying firm's business (Talluri, Narasimhan, \& Viswanathan, 2007). A 2003 study from the Center of Advanced Purchasing Studies found that such auctions reduced costs by an average of $15 \%$ and a reduced cycle time by an average of $90 \%$ (as cited in Talluri et al., 2007). IT can also be applied beyond the procurement of goods and aid in supply chain operations. Cheng et al. (2010) found that RFID can be used to enhance user understandability of a tool exchange process, therefore reducing inventory costs and changeover time.

\subsubsection{Risks and Importance}

There is tremendous value in procuring effective information technology. There is also tremendous risk. How much a firm spends on IT is not necessarily an indicator of financial performance (Kohli \& Devaraj, 2003; Qi \& Chau, 2012). A single IT purchase cannot meet every business need (Dai \& Kauffman, 2006), and firms can spend the same amount of money on IT and end up with vastly different capabilities (Kohli \& Devaraj, 2003). Additionally, suppliers' IT systems must be compatible with customers' systems in order to be useful. Therefore, purchasing an IT system is synonymous with purchasing access to a certain supplier network (Essig et al., 2015; Hingorani, 2010). There is significant risk in these purchases because they are irreversible; these are large, critically important purchases that impact the entire organization's functions, which cannot be tweaked or returned $(\mathrm{Qu}$ et al., 2011). Despite the importance and high amount of spending that goes into IT procurement, most IT purchases result in buyer's remorse (Oh et al., 2014). Many ERP systems are not equipped to deal with all types of parts, such as tooling MRO parts (Bailey \& Helms, 2007; MacDonnell \& Clegg, 2007). Dorling (2002) found less than $50 \%$ of firms have a risk management strategy for their IT procurement. 
Selecting the appropriate IT procurement strategies, therefore, is important to a firm's success. Each e-procurement technology has its advantages and disadvantages, and companies often need to take a multi-faceted approach to IT procurement based on the advantages of each strategy (Rajkumar, 2001). Oh et al. (2014) study the collaborative requirements of certain types of e-procurement. They found that extranet, a private network using the Internet where multiple parties have access, is more appropriate for developing long-term collaboration with suppliers, while the use of e-markets encourage discovery of new suppliers, but does not serve well to foster relationships. Additionally, IT systems should support the company's needs after the point of purchase. Monitoring a supplier's performance, quality, adherence to procedures, and conflict resolution are areas where problems most often arise, but are rarely addressed ahead of time (Dorling, 2002). IT procurement strategies must take into account the entire product lifecycle, as well as supplier management needs. In general, companies must be aware of the shortcomings of their selected IT strategies and compensate for their weaknesses in order to achieve greater performance (Oh et al., 2014).

\subsubsection{IT Utilization and Stakeholder Involvement}

One of the more robust areas of study when it comes to IT procurement is on the topic of IT utilization, rather than IT capability. A firm may spend money to be capable of certain processes, but if the firm does not actively utilize those processes, then the system is wasteful (Brandon-Jones \& Kauppi, 2018; Oh et al., 2014). In fact, some studies have highlighted the extent to which this occurs (Balter, 2011; Mouritsen, 2013). Some studies have focused on internal stakeholders' acceptance and utilization of the IT systems. Yu et al. (2015) separate IT capability into two categories: breadth, or how widespread knowledge is shared in the organization, and depth, or how much capability a single user can have. It was found that while both variables contribute to success, breadth (understood as organizational acceptance) is more important and more difficult to achieve than depth (understood as individual capability). This is corroborated by our earlier examples of maverick buying for non-critical MRO parts; the top two reasons for maverick purchasing were lack of awareness or lack of ability due to process insufficiency (Karjalainen et al., 2009). Brandon-Jones and Kauppi (2018) state that IT adoption and IT acceptance are often erroneously assumed to happen instantaneously upon purchase of IT systems. Instead, they suggest a three-step framework for the acceptance and eventual performance and utilization of IT systems, found in Figure 2. The "acceptance" stage is impacted by how long the system has been in place; Bendoly and Schoenherr (2005) found that organizations are much more accepting of older technologies and are risk-averse in trying new ones. In order to expedite the acceptance process so as to more quickly achieve performance, senior leaders should be advocates for the new IT systems, which will then spread acceptance to individual users (Oh et al., 2014). An organization's readiness to accept new IT systems will directly affect e-procurement adoption and success (Knudsen, 2003). Customer satisfaction 


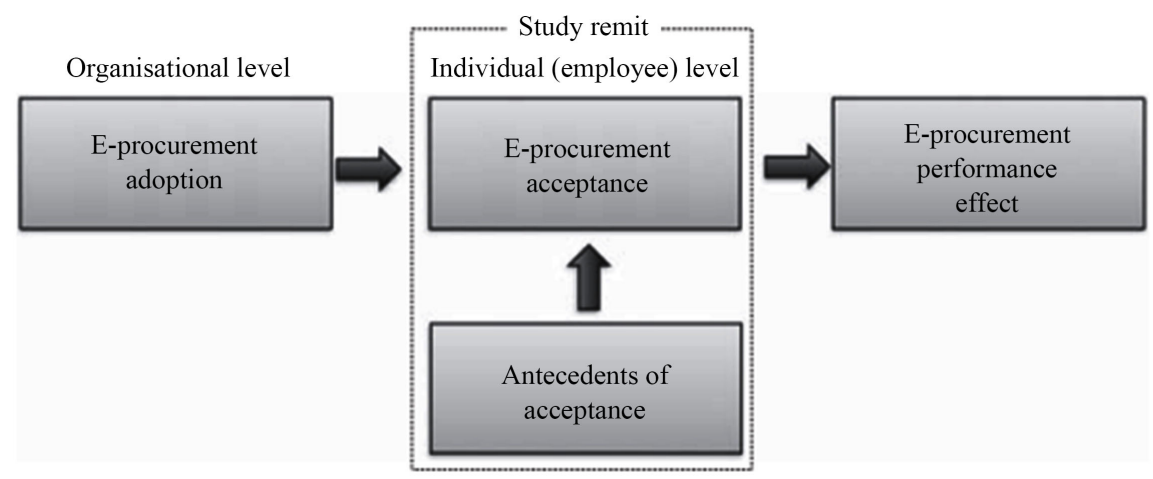

Figure 2. Examining antecedents of e-procurement acceptance, Brandon-Jones and Kauppi (2018).

is essential when implementing new technology, and since internal employees are often the end user of these systems, their needs must be studied and met (Dorling, 2002; Essig et al., 2015).

However, internal employees are not the only stakeholders in an IT procurement decision. Frequently, companies seek connections with other members in their supply chains, such as customers and suppliers. Electronic Data Interchange (EDI) and other communicative methods are frequently used in industry (Brandon-Jones \& Kauppi, 2018). Hsin, Yao-Chuan, and Che-Hao (2013) found that information sharing and supply chain integration are crucial components of supply chain performance. As such, it is important to look at the degree of both internal and external collaboration capabilities when evaluating an IT system (Oh et al., 2014). Additionally, depending on a firm's industry and IT systems, external customers interact with a firm via their IT systems. Indirect spend items are often assumed to have no interaction with the end customer, due to not affecting the end product. However, IT is one of the few examples of something under the category of indirect spend which directly affects customers and their perceptions of the business. Therefore, when applicable, end customer satisfaction is an important thing to consider when developing IT strategies (Nakata et al., 2008).

In addition to worrying about how IT systems affect the procurement of goods and services, companies must also determine how to strategically procure the IT systems themselves. Companies rarely develop their IT systems internally, and IT outsourcing has been widespread in both the public and private sector (Moon et al., 2010). IT outsourcing has been found to reduce IT operating costs, improve technical competence, and provide competitive advantages (DiRomualdo \& Gurbaxani, 1998). How beneficial IT outsourcing can depend on a firm's size and industry (Yu et al., 2015). Qu et al. (2011) found that industry concentration (the extent to which market shares are concentrated within an industry) and capital intensity (the extent to which fixed assets are required to do business in a given industry) are negatively correlated to the level of IT outsourcing. In other words, if there are high barriers to entry in both market share and cost, firms are less likely to outsource their IT. However, if IT outsourcing is deemed strategic, 
then the firm's approach to supplier management must also be decided. Heckman (1999) cites two opposing viewpoints: first, the arm's length negotiation of formal structure, relying on contracts and monitoring contract compliance, or second, the informal structure relying on trust and partnership. Qi and Chau (2012) found that the two viewpoints are mutually beneficial, rather than opposing; both are indispensable in order to have successful IT outsourcing. Both dimensions must be properly managed in order to have IT outsourcing success. Important factors identified for the contract dimension were contractual complexity and contract management, while important factors identified for the relationship dimension were trust, commitment, and shared knowledge. It is important to note that the type of relationship needed for successful IT outsourcing varies based on the relative strategic importance of the IT system. Moon et al. (2010) use the Four Outsourcing Relationship Types (FORT) framework to analyze how strategic impact and substitution costs affect supplier relationship management. They found that IT outsourcing projects are most successful when they are both strategically important and there are high substitution costs. This is likely because the high importance and limited other options forces businesses to dedicate more resources to the project. Because relationships are two-directional, provider quality must also be considered. The supplier must also be willing to support a relationship for both firms to prosper (Essig et al., 2015).

\subsubsection{Summary of IT Procurement}

IT procurement has been one of the most researched areas of indirect spending, and is a crucial antecedent to the success of the organization. Many types of e-procurement and IT systems exist, each with their respective advantages and disadvantages. Firms must select their IT strategies carefully, acknowledging the characteristics of each type of e-procurement system. Firms must also have a strategy for supplier management, balancing the need for enforcing contractual compliance with the flexibility of a trust-based relationship. Finally, firms must prioritize IT utilization rather than IT capacity, as an IT system is only as good as how it is used. In order to maximize utilization, firms must focus on generating company-wide acceptance of IT systems.

\section{Suggested Future Areas of Study}

Although growing, indirect spending remains a wide and diverse area of study that needs to be further researched (Cox et al., 2005). Much of the current research attempts to draw conclusions on larger-size businesses, with assumptions being made to extend the principles to smaller businesses. This assumption may not always be accurate. Gunasekaran et al. (2009) found that most small and medium-sized enterprises (SMEs) recognized the value of e-procurement systems and the benefits such systems could bring to their companies; however, many had not yet implemented them. In fact, many of the SME's purchasing departments consisted of $1-5$ people. It would be interesting to see if there 
would be a change in something such as maverick buying with such a small purchasing department; would maverick buying decrease due to manageability, or would it proliferate due to a lack of management systems? Additionally, much of the current research has been focused on the manufacturing industry, rather than service (Sitar, 2012; van der Valk \& Rozemeijer, 2009). While outsourcing of some services has been studied, such as in the areas of tooling MRO and IT, more research must be done for firms that are in the service industry prior to outsourcing. Additionally, while many articles highlight the importance of leadership alignment with indirect spend strategies, few (if any) tackle the topic of how to accomplish this. Given the often-stressed importance of leadership alignment, this is an area of future research (Brandon-Jones \& Kauppi, 2018; Karjalainen et al., 2009).

\section{A Framework for Indirect Procurement}

In 2014, when global certification and training firm COPC Inc. planned the development of standards for indirect procurement, industry executives responsible for organizations were asked to participate in the project. Many of those executives were graduates of the Western Michigan University (WMU) Integrated Supply Management (ISM) program. And, when COPC identified the need for academic leadership for the project, it tapped faculty resources from the WMU Center for Integrated Supply Management. Companies are only now starting to look at their indirect procurement from a strategic perspective. The COPC Indirect Procurement Standard not only meets academic rigor but satisfies real-life business needs for today's procurement professionals.

COPC announced the publication of the Indirect Procurement Standard, a set of best practices and key metrics for any company seeking to manage its indirect spending strategically. The standard is a comprehensive system for managing procurement operations and covers five areas-leadership and planning; business processes; support processes; people processes; and performance. The goal is to help companies create efficient and high-performing procurement operations that provide indirect goods and services at an optimal value-balancing cost, quality and risk.

A variety of companies stepped in to help with the project, including Microsoft, Abbott, Cisco, Hewlett Packard Enterprise, Harley-Davidson, Google, Eaton, Intuit, Magna International, Under Armour, Perrigo, BAE Systems, Nike, and Stryker. The standard was an essential step in ensuring companies can implement appropriate best practices and benefit from the latest knowledge in this evolving area. The WMU ISM curriculum was an academic leader in developing indirect procurement curriculum in response to industry needs. Several years ago, managers addressed the faculty at WMU regarding the lack of indirect procurement training in curricula. The indirect space was developing into a strategic discipline that required a formal education where very little was offered. The ISM program responded by building indirect content that puts it at the forefront 
of the specialty. Since that time, the discipline has grown so much that industry was starting to demand a framework to guide its indirect processes. This standard, the first of its kind in the indirect space, can be downloaded at: https://indirectpro.com/copc-indirect-procurement-standard/.

\section{Conclusion}

Indirect spend represents a small but crucial portion of a firm's expenditures. While the focus has historically been given to direct expenditures, a growing body of research is investigating how to properly manage indirect spend. However, the research is still in its nascent stages, and suffers from an unnecessarily complex taxonomy. Indirect spend represents both the dull and the dire, and more research has to be done to better understand the current state of management of this diverse category. Most current research focuses on MRO (both non-critical and tooling) and IT purchasing, with increasing focus being placed on supplier relationship management and employee involvement. As business continues to prioritize services over manufacturing, it is becoming more important to analyze and manage the costs that are not related to the product or service being sold.

\section{Conflicts of Interest}

The authors declare no conflicts of interest regarding the publication of this paper.

\section{References}

Agndal, H., \& Nilsson, U. (2007). Activity-Based Costing: Effects of Long-Term BuyerSupplier Relationships. Qualitative Research in Accounting and Management, 4, 222. https://doi.org/10.1108/11766090710826655

Al-Kaabi, H., Potter, A., \& Naim, M. (2007a). An Outsourcing Decision Model for Airlines' MRO Activities. Journal of Quality in Maintenance Engineering, 13, 217-227. https://doi.org/10.1108/13552510710780258

Al-Kaabi, H., Potter, A., \& Naim, M. (2007b). Insights into the Maintenance, Repair, and Overhaul Configurations of European Airlines. Journal of Air Transportation, 12, 27-42.

Angeles, R., \& Nath, R. (2007). Business-to-Business e-Procurement: Success Factors and Challenges to Implementation. Supply Chain Management, 12, 104. https://doi.org/10.1108/13598540710737299

Anonymous (2015). Procurement Professionals Split on Tackling Maverick Spend. Supply Management, 20, 8.

Ayeni, P., Ball, P., \& Baines, T. (2016). Towards the Strategic Adoption of Lean in Aviation Maintenance Repair and Overhaul (MRO) Industry. Journal of Manufacturing Technology Management, 27, 38-61. https://doi.org/10.1108/JMTM-04-2015-0025

Bailey, G. J., \& Helms, M. M. (2007). MRO Inventory Reduction-Challenges and Management: A Case Study of the Tennessee Valley Authority. Production Planning \& Control, 18, 261. https://doi.org/10.1080/09537280601127351

Balter, B. J. (2011). Toward a More Agile Government: The Case for Rebooting Federal IT Procurement. Public Contract Law Journal, 41, 149-171. 
Barry, J., Cavinato, J. L., Green, A., \& Young, R. R. (1996). A Development Model of Effective MRO Procurement. International Journal of Purchasing and Material Management, 32, 35-44. https://doi.org/10.1111/j.1745-493X.1996.tb00284.x

Bechtel, C., \& Patterson, J. L. (1997). MRO Partnerships: A Case Study. International Journal of Purchasing and Materials Management, 33, 18-23. https://doi.org/10.1111/j.1745-493X.1997.tb00027.x

Bendoly, E., \& Schoenherr, T. (2005). ERP System and Implementation-Process Benefits: Implications for B2B e-Procurement. International Journal of Operations \& Production Management, 25, 304-319. https://doi.org/10.1108/01443570510585516

Brandon-Jones, A., \& Kauppi, K. (2018). Examining the Antecedents of the Technology Acceptance Model within e-Procurement. International Journal of Operations \& Production Management, 38, 22-42. https://doi.org/10.1108/IJOPM-06-2015-0346

Carayannis, E. G., \& Popescu, D. (2005). Profiling a Methodology for Economic Growth and Convergence: Learning from the EU e-Procurement Experience for Central and Eastern European Countries. Technovation, 25, 1-14. https://doi.org/10.1016/S0166-4972(03)00071-3

Cheng, C., Barton, D., \& Prabhu, V. (2010). The Servicisation of the Cutting Tool Supply Chain. International Journal of Production Research, 48, 1-19. https://doi.org/10.1080/00207540802389235

Cox, A., Chicksand, D., Ireland, P., \& Davies, T. (2005). Sourcing Indirect Spend: A Survey of Current Internal and External Strategies for Non-Revenue Generating Goods and Services. Journal of Supply Chain Management, 41, 39-51. https://doi.org/10.1111/j.1055-6001.2005.04102004.x

Croom, S. (2000). The Impact of Web-Based Procurement on the Management of Operating Resources Supply. Journal of Supply Chain Management, 36, 4-13. https://doi.org/10.1111/j.1745-493X.2000.tb00065.x

Croom, S. (2001). Restructuring Supply Chains through Information Channel Innovation. International Journal of Operations \& Production Management, 21, 504-515. https://doi.org/10.1108/01443570110381408

Dai, Q., \& Kauffman, R. J. (2006). To Be or Not to B2B: Evaluating Managerial Choices for e-Procurement Channel Adoption. Information Technology and Management, 7, 109-130. https://doi.org/10.1007/s10799-006-8103-9

de Boer, L., Harink, J., \& Heijboer, G. (2002). A Conceptual Model for Assessing the Impact of Electronic Procurement. European Journal of Purchasing and Supply Management, 8, 25-33. https://doi.org/10.1016/S0969-7012(01)00015-6

de Boer, L., Holmen, E., \& Sitar, C. P. (2003). Purchasing as an Organizational Design Problem: The Case of Non-Product Related Items and Services. Management Decision, 41, 911-922. https://doi.org/10.1108/00251740310500903

DiRomualdo, A., \& Gurbaxani, V. (1998). Strategic Intent for IT Outsourcing. Sloan Management Review, 39, 67-80.

Dorling, A. (2002). Successful Information Technology Procurement. Software Quality Professional, 4, 21.

Essig, M., Glas, A. H., \& Gutsmiedl, J. (2015). Procurement of a Supply Information System. Journal of Enterprise Information Management, 28, 377-399. https://doi.org/10.1108/JEIM-01-2014-0008

Gunasekaran, A., \& Ngai, E. W. T. (2008). Adoption of e-Procurement in Hong Kong: An Empirical Research. International Journal of Production Economics, 113, 159. https://doi.org/10.1016/j.ijpe.2007.04.012 
Gunasekaran, A., McGaughey, R. E., Ngai, E. W. T., \& Rai, B. K. (2009). E-Procurement Adoption in the Southcoast SMEs. International Journal of Production Economics, 122, 161. https://doi.org/10.1016/j.ijpe.2009.05.013

Guo, L., \& Ng, I. (2011). The Co-Production of Equipment-Based Services: An Interpersonal Approach. European Management Journal, 29, 43. https://doi.org/10.1016/j.emj.2010.08.005

Han, K., Kauffman, R. J., \& Nault, B. R. (2011). Returns to Information Technology Outsourcing. Information Systems Research, 22, 824-840+886-887. https://doi.org/10.1287/isre.1100.0290

Hawkins, T. G., Nissen, M. E., \& Rendon, R. G. (2014). Leveraging Strategic Sourcing and Knowledge Management to Improve the Acquisition of Knowledge-Based Services. Journal of Public Procurement, 14, 215-251. https://doi.org/10.1108/JOPP-14-02-2014-B003

Heckman, R. (1999). Organizing and Managing Supplier Relationships in Information Technology Procurement. International Journal of Information Management, 19, 141-155. https://doi.org/10.1016/S0268-4012(99)00005-5

Hingorani, N. (2010). Domino Effect. Risk Management, 57, 56-58+60+62.

Hsin, H. C., Yao-Chuan, T., \& Che-Hao, H. (2013). E-Procurement in Supply Chain Performance. Supply Chain Management, 18, 34-51. https://doi.org/10.1108/13598541311293168

Karjalainen, K., Kemppainen, K., \& van Raaij, E. M. (2009). Non-Compliant Work Behavior in Purchasing: An Exploration of Reasons behind Maverick Buying. Journal of Business Ethics, 85, 245-261. https://doi.org/10.1007/s10551-008-9768-2

Kim, J., \& Shunk, D. L. (2003). Matching Indirect Procurement Process with Different B2B e-Procurement Systems. Computers in Industry, 53, 153-164. https://doi.org/10.1016/j.compind.2003.07.002

Knudsen, D. (2003). Aligning Corporate Strategy and e-Procurement Tools. International Journal of Physical Distribution \& Logistics Management, 33, 720-734. https://doi.org/10.1108/09600030310502894

Kohli, R., \& Devaraj, S. (2003). Measuring Information Technology Payoff: A Meta-Analysis of Structural Variables in Firm-Level Empirical Research. Information Systems Research, 14, 127. https://doi.org/10.1287/isre.14.2.127.16019

Lancioni, R. A., Smith, M. F., \& Schau, H. J. (2003). Strategic Internet Application Trends in Supply Chain Management. Industrial Marketing Management, 32, 211-217. https://doi.org/10.1016/S0019-8501(02)00264-X

MacDonnell, M., \& Clegg, B. (2007). Designing a Support System for Aerospace Maintenance Supply Chains. Journal of Manufacturing Technology Management, 18, 139-152. https://doi.org/10.1108/17410380710722863

Moon, J., Swar, B., Choe, Y. C., Chung, M., \& Jung, G. H. (2010). Innovation in IT Outsourcing Relationships: Where Is the Best Practice of IT Outsourcing in the Public Sector? Innovation: Management, Policy \& Practice, 12, 217-226. https://doi.org/10.5172/impp.12.2.217

Mouritsen, M. (2013). Is Your Organization Managing or Mangling Its Technology Assets? Strategic Finance, 94, 35-41.

Nakata, C., Zhu, Z., \& Kraimer, M. L. (2008). The Complex Contribution of Information Technology Capability to Business Performance. Journal of Managerial Issues, 20, 485-506.

Oh, S., Yang, H., \& Kim, S. W. (2014). Managerial Capabilities of Information Technolo- 
gy and Firm Performance: Role of e-Procurement System Type. International Journal of Production Research, 52, 4488-4506. https://doi.org/10.1080/00207543.2013.867084

Palma-Mendoza, J. A., \& Neailey, K. (2015). A Business Process Re-Design Methodology to Support Supply Chain Integration: Application in an Airline MRO Supply Chain. International Journal of Information Management, 35, 620-631. https://doi.org/10.1016/j.ijinfomgt.2015.03.002

Palmer, R. J., \& Ward, W. D. (1997). Charge It! Journal of Accountancy, 184, 51-54. https://doi.org/10.1038/scientificamerican0251-54

Porter, A. M. (1999). Taking Control of 'Indirect' Corporate Spending. Purchasing, 127, 55-60.

Qi, C., \& Chau, P. Y. K. (2012). Relationship, Contract and IT Outsourcing Success: Evidence from Two Descriptive Case Studies. Decision Support Systems, 53, 859-869. https://doi.org/10.1016/j.dss.2012.05.018

Qu, W. G., Pinsonneault, A., \& Oh, W. (2011). Influence of Industry Characteristics on Information Technology Outsourcing. Journal of Management Information Systems, 27, 99-128. https://doi.org/10.2753/MIS0742-1222270404

Rajkumar, T. (2001). E-Procurement: Business and Technical Issues. Information Systems Management, 18, 52-60. https://doi.org/10.1201/1078/43198.18.4.20010901/31465.6

Razi, M. A., \& Tarn, J. M. (2003). An Applied Model for Improving Inventory Management in ERP Systems. Logistics Information Management, 16, 114-124. https://doi.org/10.1108/09576050310467250

Rezaei Somarin, A., Asian, S., Jolai, F., \& Chen, S. (2018). Flexibility in Service Parts Supply Chain: A Study on Emergency Resupply in Aviation MRO. International Journal of Production Research, 56, 3547-3562. https://doi.org/10.1080/00207543.2017.1351640

Sarkar, A., \& Mohapatra, P. K. J. (2008). Maximum Utilization of Vehicle Capacity: A Case for MRO Items. Computers \& Industrial Engineering, 54, 185-201. https://doi.org/10.1016/j.cie.2007.07.003

Segev, A., \& Gebauer, J. (2000). Emerging Technologies to Support Indirect Procurement: Two Case Studies from the Petroleum Industry. Information Technology and Management, 1, 107-128. https://doi.org/10.1023/A:1019160605755

Sharifi, M., Kwon, R. H., \& Jardine, A. K. S. (2016). Valuation of Performance-Based Contracts for Capital Equipment: A Stochastic Programming Approach. The Engineering Economist, 61, 1-22. https://doi.org/10.1080/0013791X.2015.1081711

Sitar, C. P. (2012). Purchasing Management of Business Services in the Contemporary Knowledge Based Economy. Annales Universitatis Apulensis: Series Oeconomica, 14, 286-293.

Sodhi, M. S., Sodhi, N. S., \& Tang, C. S. (2014). An EOQ Model for MRO Customers under Stochastic Price to Quantify Bullwhip Effect for the Manufacturer. International Journal of Production Economics, 155, 132-142. https://doi.org/10.1016/j.ijpe.2013.12.020

Sople, V. (2016). MRO Supply Chain Striving for Operational Efficiency. International Journal of Business Insights and Transformation, 10, 40-45.

Talluri, S., Narasimhan, R., \& Viswanathan, S. (2007). Information Technologies for Procurement Decisions: A Decision Support System for Multi-Attribute e-Reverse Auctions. International Journal of Production Research, 45, 2615-2628. https://doi.org/10.1080/00207540601020585 
Thomas, A. J., Mason-Jones, R., Davies, A., \& John, E. G. (2015). Reducing Turn-Round Variability through the Application of Six Sigma in Aerospace MRO Facilities. Journal of Manufacturing Technology Management, 26, 314-332. https://doi.org/10.1108/JMTM-05-2013-0052

van der Valk, W., \& Rozemeijer, F. (2009). Buying Business Services: Towards a Structured Service Purchasing Process. The Journal of Services Marketing, 23, 3-10. https://doi.org/10.1108/08876040910933048

Van Weele, A. J. (2005). Purchasing and Supply Chain Management: Analysis, Strategy, Planning, and Practice (4th ed.). London: Thomson Learning.

Wu, F., Yeniyurt, S., Kim, D., \& Cavusgil, S. T. (2006). The Impact of Information Technology on Supply Chain Capabilities and Performance: A Resource-Based View. Industrial Marketing Management, 35, 492-504. https://doi.org/10.1016/j.indmarman.2005.05.003

Xideas, E., \& Moschuris, S. (1998). The Influence of Product Type on the Purchasing Structure. European Journal of Marketing, 32, 974-992. https://doi.org/10.1108/03090569810243587

Yates, J. (1998). Corporate Purchasing Cards Are Hitting Their Stride. Management Accounting, $80,45-45+47$.

Yu, S., Mishra, A. N., Gopal, A., Slaughter, S., \& Mukhopadhyay, T. (2015). E-Procurement Infusion and Operational Process Impacts in MRO Procurement: Complementary or Substitutive Effects? Production and Operations Management, 24, 1054-1070.

https://doi.org/10.1111/poms.12362 